\title{
EFFECT OF THERMAL TREATMENT ON PHYSICAL AND MECHANICAL PROPERTIES OF BIRCH AND PINE WOOD
}

\author{
Andis Antons ${ }^{1}$, Dace Cirule ${ }^{1}$, Anrijs Verovkins ${ }^{1}$, Edgars Kuka ${ }^{1,2}$ \\ ${ }^{1}$ Lavian State Institute of Wood Chemistry, Latvia \\ ${ }^{2}$ Riga Technical University, Latvia \\ antonsandis@tvnet.lv
}

\begin{abstract}
No simple method has yet been found for satisfactory wood bio-resistance improvement regarding material performance in its end-use. An attempt to obtain material with proper strength and bio-durability by combined wood thermal modification and impregnation with a biocide is being researched. To select the most appropriate treatment conditions for the combined process, changes in wood physical and mechanical properties depending on the treatment temperature were investigated in the present study. For the investigation, in Latvia the most widespread wood softwood pine (Pinus sylvestris L.) and hardwood birch (Betula spp.) was used. Changes of wood mechanical and physical properties due to thermal modification were investigated and effect of treatment temperature and relative humidity on wood characteristics evaluated. It was found that, due to different degree of changes, no identical treatment conditions suit for birch and pine wood. Birch wood is considerably more sensitive to temperature and acceptable strength was maintained only for birch wood treated at $150{ }^{\circ} \mathrm{C}$ and for pine wood treated at $160{ }^{\circ} \mathrm{C}$. Nevertheless at higher environmental humidity equilibrium moisture content and consequently radial and tangential swelling increased for all studied wood types, substantially smaller changes due to elevated humidity were detected for modified wood.
\end{abstract}

Key words: thermal treatment, birch, pine, hardness, bending strength, swelling, capillary water uptake.

\section{Introduction}

Over recent decades, different treatment methods have been proposed for restriction of such wood drawbacks as dimensional instability and low resistance to biodegradation (Homan \& Jorissen, 2004; Gerardin, 2016). Commercially the most successful has been wood thermal modification and different treatment processes have been introduced in production on industrial scale (Hill, 2006). One advantage of wood thermal modification in comparison with other wood modification methods is that no chemicals are used to alter wood properties as the changes are caused by autocatalytic reactions of wood chemical components during its exposure to elevated temperature. This makes wood thermal modification relatively environmentally friendly (Sandberd, Haller, \& Navi, 2013). Another advantage is that the equipment is simple and comparatively low capital expenditure is needed to launch manufacturing. Therefore, it is foreseen that thermal modification of wood will continue growing (Militz \& Altgen, 2014).

A lot of different wood thermal modification methods are known which vary with the treatment atmosphere, temperature, and duration (Hofmann et al., 2013; Militz \& Altgen, 2014; Gerardin, 2016). They all include exposure of wood to elevated temperature $\left(150-260{ }^{\circ} \mathrm{C}\right)$ in absence of oxygen which result in complex reactions including certain destruction of low-molecular substances and hemicelluloses, reorganisation of lignin and cellulose and evaporation of volatile compounds (Sandberd, Haller, \& Navi, 2013). These wood chemical transformations result in changed wood colour, improved dimensional stability and enhanced bio-durability. However, alteration of wood chemical composition and structure due to thermal treatment causes reduction in wood mechanical strength (Boonstra et al., 2007; Arnold, 2010; Welzbacher et al., 2011; Widmann, FernandezCabo, \& Steiger, 2012). Therefore, when selecting the modification method and processing parameters, it is important to find a trade-off between benefits and losses taking into consideration the requirements for the material end-use.

Despite numerous investigations, no simple method has been found yet for fully satisfactory result regarding material potential performance in its enduse. Thus, different combined treatment processes, including pre- or post-treatment of thermally modified wood, are now intensively investigated and the results are being reported (Ahmed, Hansson, \& Moren, 2013; Ferrari et al., 2013; Wang, Zhu, \& Cao, 2013). The present research is a part of the investigation aimed at improving wood bio-durability by combined wood thermal treatment and impregnation with a commercial biocide. It is found that substantial enhancement of bio-durability can only be reached by wood thermal treatment at the temperature range at which wood mechanical strength significantly decreases consequently restricting the application area of the material (Kamdem, Pizzi, \& Jermannaud, 2002; Metsä-Korteleinen \& Viitanen, 2010; Candelier et al., 2017). It is expected that by applying the proposed combined treatment process a material with decent mechanical strength and meeting the requirements of the use class 3 according to the EN 335-1 standard will be obtained. 
The objective of the present study was to evaluate changes in wood physical and mechanical properties due to thermal modification depending on the treatment temperature. It will let select the treatment conditions for the combined process. For the investigation, in Latvia the most widespread wood - softwood pine (Pinus sylvestris L.) and hardwood birch (Betula spp.) was used.

\section{Materials and Methods}

For the thermal modification, kiln-dried boards of birch (Betula spp.) and pine (Pinus sylvestris L.) wood measuring $700 \times 100 \times 25 \mathrm{~mm}$ were used. The modification was carried out in a multifunctional wood modification device of WTT (Denmark) production. The boards were thermally modified in a water vaper medium under elevated pressure (0.6 - 0.8 MPa depending on the temperature) for $1 \mathrm{~h}$ at the peak temperature. Each of the wood species was treated at three peak temperatures: birch wood at 150,160 and $170{ }^{\circ} \mathrm{C}$ and pine wood at 160,170 and $180{ }^{\circ} \mathrm{C}$. The boards were weighed before and after modification and mass losses calculated. The modified boards were conditioned (RH $65 \pm 5 \%$; $20 \pm 2{ }^{\circ} \mathrm{C}$ ) for at least two weeks before preparing specimens for testing mechanical and physical properties.

Determination of wood equilibrium moisture content (EMC) and wood radial and tangential swelling was performed with specimens measuring $20 \times 20 \times 10 \mathrm{~mm}(\mathrm{r} \times \mathrm{t} \times \mathrm{l})$ and having the annual ring orientation strictly parallel to the edge. Ten replicates were used per each modification temperature and the untreated wood. Before starting the test, specimens were oven-dried $\left(102 \pm 2{ }^{\circ} \mathrm{C}\right)$ and their mass (with accuracy of $0.0002 \mathrm{~g}$ ) and dimensions (with accuracy of $0.02 \mathrm{~mm}$ ) were determined. Further the specimens were conditioned until reaching constant weight at $20 \pm 2{ }^{\circ} \mathrm{C}$ temperature and fixed relative humidity $(\mathrm{RH})$ conditions in increasing sequence:

$45 \%, 65 \%, 85 \%$. The specimen equilibrium mass and dimensions were recorded for each tested $\mathrm{RH}$ and calculations according to DIN 520184 were performed to establish wood swelling characteristics. The moisture exclusion efficiency (MEE) was calculated as given below (Eq. 1).

$$
\mathrm{MEE}=\frac{E M C_{\text {unmod }}-E M C_{\text {mod }}}{E M C_{\text {unmod }}} \times 100, \%
$$

Capillary water uptake (CWU) through radial and tangential surfaces was tested using cubic specimens $(20 \times 20 \times 20 \mathrm{~mm})$ with annual ring and grain orientations strictly parallel to the edges. All sides, except two opposite faces (radial or tangential), one of which was intended for CWU evaluation, were sealed with waterproof coating. After conditioning (RH $65 \pm 5 \%$; $20 \pm 2{ }^{\circ} \mathrm{C}$ ) until constant weight, the specimens were installed into a frame that restricted water evaporation from the container and fixed the specimens in a position in which the contact surface was $2 \pm 0.2 \mathrm{~mm}$ under the water. The container was filled with distilled water the level of which was monitored and adjusted every day. After 10 days, the specimens were removed from the water, excess water wiped off with a paper towel and the specimen weight recorded with an accuracy of $0.0002 \mathrm{~g}$. The experiment was carried out in a room with controlled $\mathrm{RH}(65 \pm 2 \%)$ at $20 \pm 2{ }^{\circ} \mathrm{C}$. Ten replicates were used per each wood type.

Wood bending strength was determined according to DIN 52186 in a three-point bending test using a material strength testing device ZWICK Z100. Before the test was carried out, the specimens measuring $360 \times 20 \times 20 \mathrm{~mm}$ with the fibres parallel to the sample longitudinal axis were conditioned at two different RH (65\% and 85\%) till constant mass. At least 30 specimens obtained from different boards were tested for each modification and RH. The loading speed was adjusted for each of wood type to reach the destruction maximum within $90 \pm 10 \mathrm{sec}$.

Wood surface hardness was determined according to the Brinell test procedure and meeting the requirements of the EN 1534 standard. The hardness for radial and tangential directions of specimens conditioned till constant mass at two RH (65\% and $85 \%$ ) were evaluated. A force of $1 \mathrm{kN}$ was applied with reaching it within $15 \mathrm{sec}$ and maintaining it for 25 sec by using a universal test device ZWICK Z100 and a metal ball of diameter $8 \mathrm{~mm}$ as an intender. Ten specimens were examined for each wood type and eight measurements were performed on radial and tangential surfaces of each specimen.

\section{Results and Discussion}

Density of wood before and after THT as well as mass loss due to thermal treatment, are presented in Table1.

The wood mass loss increases with increasing THT temperature for both species at the temperature range used in the study. However, birch wood is considerably more sensitive to temperature compared to pine as equal mass losses are detected for birch at $160{ }^{\circ} \mathrm{C}$ and pine at $170{ }^{\circ} \mathrm{C}$. Other authors have also reported similar findings (Rowell et al., 2009; Chaouch et al., 2010). It is explained by higher content of hemicelluloses, lower content of lignin and high content of syringyl groups in hardwood. Unlike the mass loss, the density dependence on temperature is significantly less pronounced and, compared to the initial material, the decrease for both woods varies in the range of $7-8 \%$.

Examination of wood mechanical properties showed that both bending strength and hardness 
Oven-dry wood density and mass losses due to thermal treatment (THT)

Table 1

\begin{tabular}{|l|c|c|c|c|c|c|c|c|}
\hline \multicolumn{1}{|c|}{ Wood } & \multicolumn{4}{|c|}{ Birch } & \multicolumn{5}{c|}{ Pine } \\
\hline \multicolumn{1}{|c|}{ Treatment } & unmodified & THT 150 & THT 160 & THT 170 & unmodified & THT 160 & THT 170 & THT 180 \\
\hline$\rho, \mathrm{g} \mathrm{cm}^{-3}$ & 0.618 & 0.593 & 0.578 & 0.577 & 0.481 & 0.471 & 0.444 & 0.467 \\
\hline STDEV & 0.046 & 0.045 & 0.07 & 0.072 & 0.053 & 0.043 & 0.055 & 0.049 \\
\hline Mass loss, \% & - & 0.1 & 6.6 & 15.7 & - & 1.2 & 6.8 & 10.6 \\
\hline
\end{tabular}

Brinell hardness, HBS ( $\mathrm{N} \mathrm{mm}^{-2}$ ), for unmodified and modified (THT) birch and pine

Table 2

\begin{tabular}{|c|c|c|c|c|c|c|c|}
\hline \multirow{2}{*}{ Birch } & \multicolumn{2}{|c|}{ RH 65\% } & \multicolumn{2}{|c|}{ RH 85\% } & \multirow{2}{*}{ Pine } & \multicolumn{2}{|c|}{ RH 65\% } \\
\cline { 2 - 5 } \cline { 7 - 8 } & Rad direct. & Tg direct. & Rad direct. & Tg direct. & & Rad direct. & Tg direct. \\
\hline unmodified & $27.5(3.1)$ & $24.0(2.7)$ & $19.7(2.0)$ & $18.4(1.7)$ & unmodified & $16.8(2.8)$ & $18.3(3.2)$ \\
\hline THT150 & $22.3(3.4)$ & $17.7(3.0)$ & $17.9(2.7)$ & $15.4(1.5)$ & THT160 & $14.4(3.2)$ & $13.8(2.5)$ \\
\hline THT160 & $18.7(3.2)$ & $15.7(3.2)$ & $13.4(1.6)$ & $13.6(1.5)$ & THT170 & $13.4(2.0)$ & $13.8(2.9)$ \\
\hline THT170 & $18.3(2.3)$ & $14.2(1.9)$ & $13.2(1.4)$ & $11.5(1.3)$ & THT180 & $13.1(2.2)$ & $13.4(1.9)$ \\
\hline
\end{tabular}

(standard deviation in parentheses).

decrease with increasing treatment temperature (Table 2 and 3). For samples conditioned at RH of $65 \%\left(20^{\circ} \mathrm{C}\right)$, it was found that untreated pine wood is relatively soft with its Brinell hardness being approximately $16-18 \mathrm{~N} \mathrm{~mm}^{-2}$. Treating of pine at the THT temperature range $160-180{ }^{\circ} \mathrm{C}$, results in wood hardness decrease by $18-23 \%$ in the radial direction and by $19-23 \%$ in the tangential direction. However, increase of the THT temperature by $20^{\circ} \mathrm{C}$, causes hardness decrease by only $4-5 \%$, whereas hardness reduction by 16 - 33\% in the radial direction and by $27-48 \%$ in the tangential direction was detected for birch after THT treatment. Moreover, birch wood is affected to a greater extent by THT with hardness decrease almost twice due to rising the treatment temperature by $20^{\circ} \mathrm{C}$ (from $150{ }^{\circ} \mathrm{C}$ to $170{ }^{\circ} \mathrm{C}$ ). The birch wood surface hardness loss is significant, and it is an important indicator, especially for the articles subjected to horizontal loads (e.g., terraces).

Bending strength is more affected by thermal modification than hardness. Already at lower treatment temperatures, the bending strength for birch and pine decreases by 33\% and 34\%, respectively (Tables 3 and 4). The decrease in bending strength is close to linear within a modification temperature range of $160-180{ }^{\circ} \mathrm{C}$ for pine. For birch, the largest decrease in bending strength is caused by the increase in temperature from $150{ }^{\circ} \mathrm{C}$ to $160^{\circ} \mathrm{C}$. At the maximum treatment temperature of $170{ }^{\circ} \mathrm{C}$, the bending strength for birch wood decreases by $56 \%$. Bending strength for pine wood at this temperature decreases by $51 \%$ and by $60 \%$, if the treatment temperature is increased up to $180^{\circ} \mathrm{C}$.

It is well known that the RH of the environment substantially affects wood properties (Simpson \& TenWolde, 1999). For both unmodified and thermally modified samples conditioned at higher $\mathrm{RH}$, the mechanical strength is significantly reduced comparing with samples conditioned at lower $\mathrm{RH}$ (Tables 2 and 3). At RH 85\% for untreated pine, bending strength decreases by $25 \%$, but for birch by $32 \%$, compared to similar parameters at $\mathrm{RH}$ $65 \%$. However, for thermally modified wood, the decrease in bending strength at elevated humidity is

Bending strength (MPa) for unmodified and modified (THT) birch and pine

Table 3

\begin{tabular}{|c|c|c|c|c|c|}
\hline Birch & RH 65\% & RH 85\% & Pine & RH 65\% & RH 85\% \\
\hline unmodified & $116.8(16.4)$ & $79.2(10.4)$ & unmodified & $93.4(13.9)$ & $69.6(8.9)$ \\
\hline THT 150 & $78.7(18.9)$ & $60.2(14.1)$ & THT 160 & $61.5(15.9)$ & $47.8(11.7)$ \\
\hline THT 160 & $57.9(15.5)$ & $41.2(8.6)$ & THT 170 & $46.2(18.3)$ & $40.3(18.1)$ \\
\hline THT 170 & $59.2(17.2)$ & $40.7(13.2)$ & THT 180 & $37.8(19.6)$ & $33.2(12.7)$ \\
\hline
\end{tabular}

(standard deviation in parentheses). 


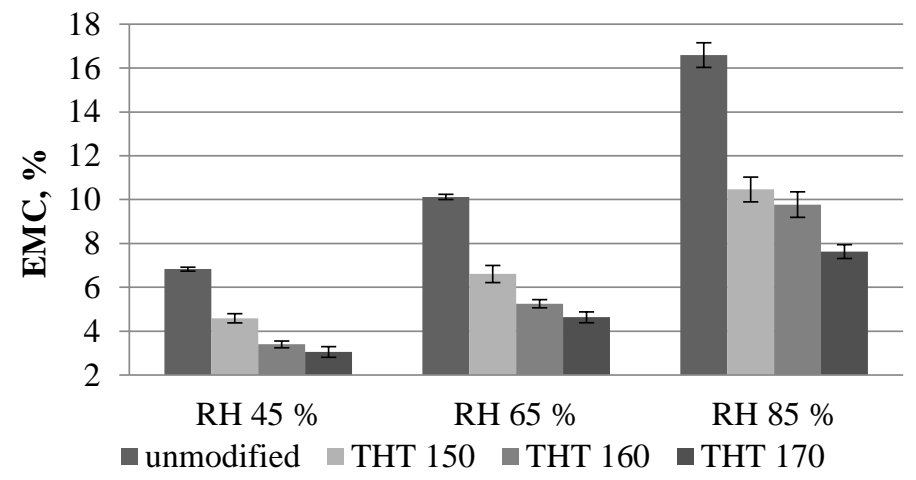

Figure 1. Birch equilibrium moisture (EMC) \% with standard deviation, depending on the air RH and THT temperature.

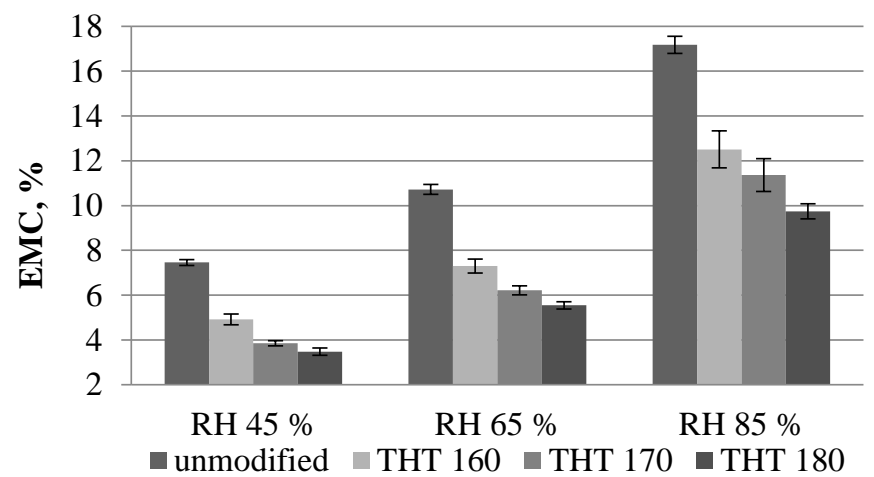

Figure 2. Pine equilibrium moisture (EMC) \% with standard deviation, depending on the air RH and THT temperature.

significantly smaller. Similar trend has been reported by Arnold (2010). However, different results were obtained for thermally modified pine and birch wood regarding the effect of treatment temperature on strength reduction due to elevated $\mathrm{RH}$. The reduction in bending strength of pine caused by rising $\mathrm{RH}$ decreased with increase in THT temperature. For the THT treated birch wood the decrease does not depend on the modification temperature. Similar effect of elevated RH was observed also with respect to the surface hardness of both tree species. The surface hardness of unmodified pine decreases by $29 \%$ in the radial direction and by $34 \%$ in the tangential direction. The surface hardness of THT pine wood also decreased but to a level that measuring failed and therefore no data on pine at $\mathrm{RH}$ 85\% are presented in the table. The unmodified birch surface hardness decreases by $34 \%$ in the radial direction and by $23 \%$ in the tangential direction, compared to the samples conditioned at RH $65 \%$. For the birch modified at $150{ }^{\circ} \mathrm{C}$, the conditioning at $\mathrm{RH} 85 \%$ reduces the hardness in the radial and tangential direction by $24 \%$. However, elevation of $\mathrm{RH}$ almost does not change the hardness for THT treated birch wood at higher $\left(160-170^{\circ} \mathrm{C}\right)$ temperatures. The differences between both species regarding the influence of humidity on hardness in different directions may be explained by the significantly different anatomical structure.

The changes in the wood component composition as a result of the thermal action have significant influence on the wood/moisture/water interaction. As a result of the degradation and/or mutual interactions in wood, with decreasing hydrophilic components, the equilibrium moisture, linear swelling and capillary water uptake decrease. The changes in wood EMC at different $\mathrm{RH}$ and depending on the modification temperature are presented in Fig. 1 and 2.

For both unmodified and THT wood, the EMC increases with rising $\mathrm{RH}$, but for the modified one, EMC is significantly lower and decreases with increasing treatment temperature.

MEE is an important characteristic of modified wood that shows how much the equilibrium moisture decreases by modifying wood (Van Acker et al., 2015). This characteristic implies on improvement. In accordance with the normative documents, MEE at RH $85 \%$ must be $>40 \%$. Figures 3. and 4. give MEE values for THT birch and pine.

In our case, this requirement is ensured for birch, modifying at $160^{\circ} \mathrm{C}$, whereas for pine - at only $180^{\circ} \mathrm{C}$. 


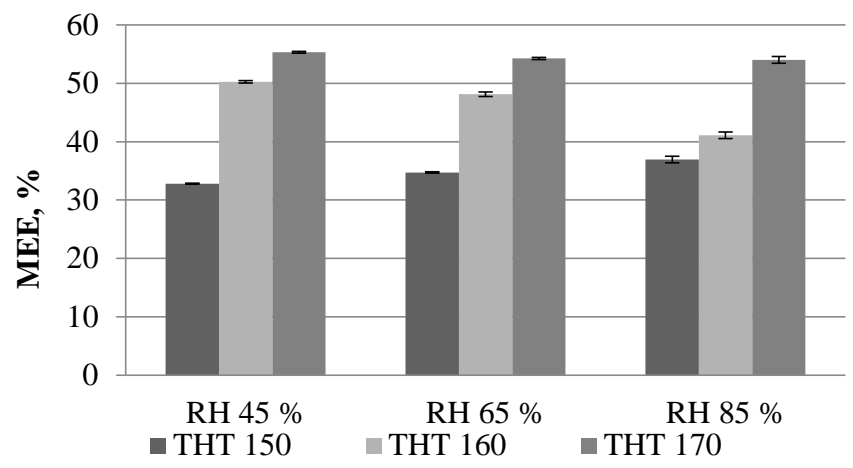

Figure 3. Moisture exclusion efficiency (MEE) with standard deviation for modified birch depending on the air RH.

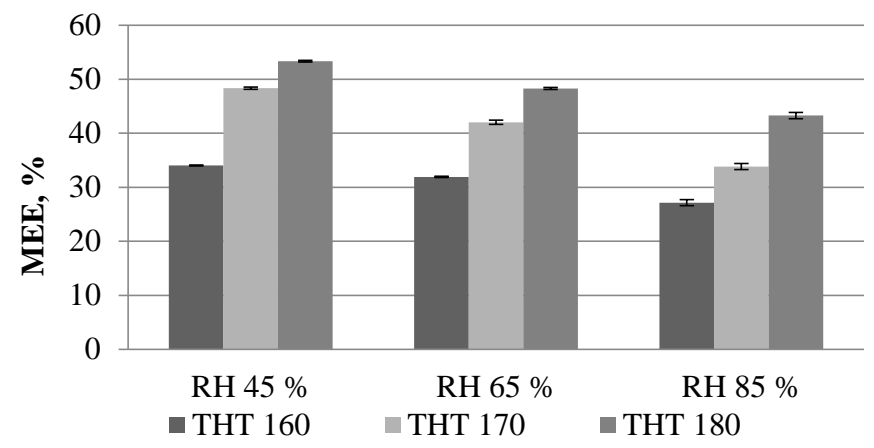

Figure 4. Moisture exclusion efficiency (MEE) with standard deviation for modified pine depending on the air RH.

The effect of thermal modification on the linear swelling of wood is shown in Table 4. As it can be seen, both the pine and birch wood swell less after thermal treatment and the swelling at similar $\mathrm{RH}$ decreases with increase in THT temperature. However, the results, obtained by soaking the wood in water up to maximum linear swelling was reached, show that there is no effect of the modification temperature on the wood dimensional stability above wood fibre saturation point. It agrees with the findings that changes in some other wood properties are dependent on the modification temperature only up to a certain

\section{Birch and pine swelling in the radial (Rad) and tangential (Tg) direction depending on the humidity (RH)}

\begin{tabular}{|c|c|c|c|c|c|c|c|c|c|}
\hline \multirow{2}{*}{\multicolumn{2}{|c|}{$\begin{array}{l}\text { Modification } \\
\text { temperature }\end{array}$}} & \multicolumn{4}{|c|}{ Rad direction } & \multicolumn{4}{|c|}{ Tg direction } \\
\hline & & RH 45\% & RH 65\% & RH 85\% & $(\max )$ & RH 45\% & RH 65\% & RH 85\% & $(\max )$ \\
\hline \multirow{4}{*}{ : } & untreated & $1.5(0.1)$ & $2.4(0.3)$ & $4.0(0.5)$ & $5.0(0.7)$ & $1.7(0.2)$ & $2.8(0.3)$ & $4.7(0.5)$ & $8.2(0.7)$ \\
\hline & THT 150 & $0.9(0.2)$ & $1.3(0.2)$ & $2.0(0.4)$ & $2.5(0.3)$ & $1.2(0.2)$ & $1.8(0.3)$ & $3.0(0.5)$ & $5.2(0.6)$ \\
\hline & THT 160 & $0.8(0.1)$ & $1.1(0.2)$ & $2.0(0.4)$ & $3.1(0.9)$ & $1.0(0.1)$ & $1.5(0.2)$ & $2.9(0.4)$ & $6.9(1.3)$ \\
\hline & THT 170 & $0.7(0.2)$ & $1.1(0.2)$ & $1.8(0.4)$ & $3.6(0.8)$ & $0.9(0.1)$ & $1.4(0.2)$ & $2.4(0.3)$ & $5.0(0.9)$ \\
\hline \multirow{4}{*}{$\stackrel{\Xi}{\Xi}$} & untreated & $1.4(0.3)$ & $2.0(0.3)$ & $3.2(0.5)$ & $5.2(0.9)$ & $2.3(0.2)$ & $3.4(0.3)$ & $5.4(0.5)$ & $9.9(0.9)$ \\
\hline & THT 160 & $0.7(0.1)$ & $1.1(0.1)$ & $2.0(0.2)$ & $3.4(0.4)$ & $1.4(0.2)$ & $2.2(0.2)$ & $3.9(0.3)$ & $6.9(0.5)$ \\
\hline & THT 170 & $0.7(0.1)$ & $1.1(0.2)$ & $1.9(0.5)$ & $3.0(0.8)$ & $1.1(0.2)$ & $1.8(0.3)$ & $3.4(0.7)$ & $5.5(1.4)$ \\
\hline & THT 180 & $0.6(0.1)$ & $1.0(0.3)$ & $1.8(0.4)$ & $3.4(0.8)$ & $0.9(0.1)$ & $1.8(0.3)$ & $3.2(0.6)$ & $6.1(0.9)$ \\
\hline
\end{tabular}

(standard deviation in parentheses). 


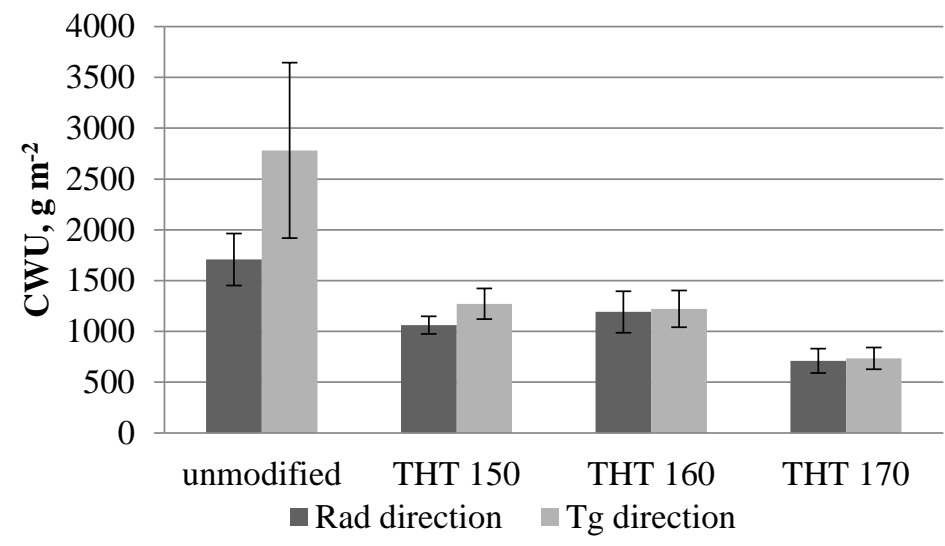

Figure 5. Capillary water uptake (CWU) with standard deviation of birch wood in the radial (Rad) and tangential (Tg) direction.

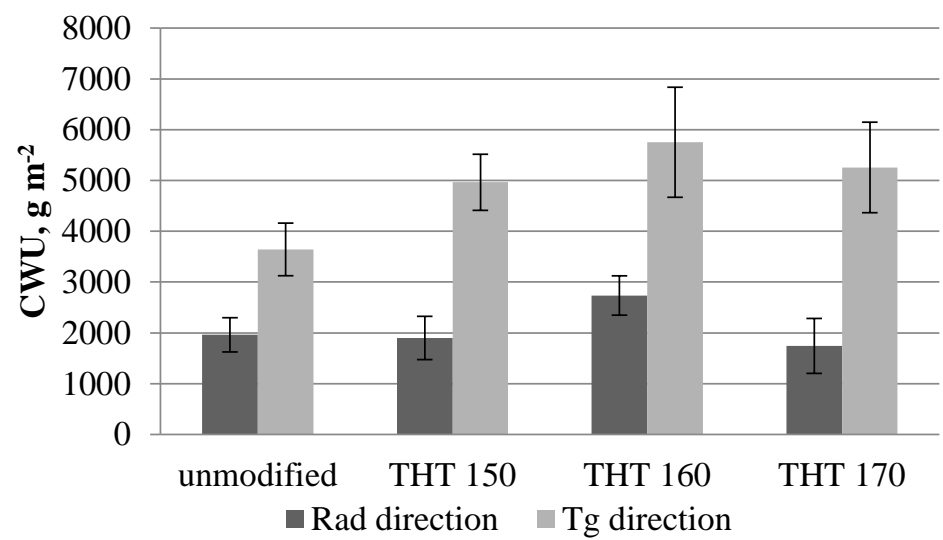

Figure 6. Capillary water uptake (CWU) with standard deviation of pine wood in the radial (Rad) and tangential (Tg) direction.

temperature range (Welzbacher, Brischke, \& Rapp, 2007).

The amount of water absorbed by birch and pine samples during 10 days of the CWU experiment is shown in Figs. 5 and 6. The unmodified pine absorbs more water than birch. However, the amount absorbed through the tangential surface is considerably larger for both unmodified birch (1.6-fold) and unmodified pine (1.9-fold). For birch, as a result of modification, the absorbed water quantities decrease through both radial and tangential surfaces. Moreover, for the modified birch, the differences between the amounts absorbed through the two surfaces are insignificant. However, the HTM treatment of pine does not reduce the CWU through the radial surface, and increases the CWU through the tangential surface. Similar effect of CWU increase has been observed also by Johansson, Sehlstedt-Persson \& Moren (2006). The explanation of the differences between the THT birch and THT pine CWU could be the differences in structural changes during thermal treatment, but it needs further research. However, these results suggest that impregnation regimes should be adjusted for each of THT treated species.

\section{Conclusions}

1. The results showed that, due to the significant strength losses during wood thermal treatment, only modification at $150{ }^{\circ} \mathrm{C}$ for birch wood and at $160{ }^{\circ} \mathrm{C}$ for pine wood is admissible to obtain intended material by the combined wood treatment.

2. The higher treatment temperatures resulted in greater improvement of wood hydrofobicidy; however, substantial decrease in wood swelling and equilibrium moisture content is obtained also at lower temperatures at which hardly any losses of wood mass were detected.

\section{Acknowledgements}

The authors gratefully acknowledge the financial support by the European Regional Development Fund project No. 1.1.1.1/16/A/133. 


\section{References}

1. Ahmed, S.A., Hansson, L., \& Moren, T. (2013). Distribution of preservatives in thermally modified scots pine and norway spruce sapwood. Wood Sci. Technol. 47(3), 499-513. DOI: 10.1007/s00226-012-0509-4.

2. Arnold, M. (2010). Effect of moisture on bending properties of thermally modified beech and spruce. $J$. Mater. Sci. 45(3), 669-680. DOI: 10.1007/s10853-009-3984-8.

3. Boonstra, M.J., Van Acker, J., Tjeerdsma, B.F., \& Kegel, E.V. (2007). Strength properties of thermally modified softwoods and its relation to polymeric structural wood constituents. Ann. For. Sci. 64(7), 679690. DOI: $10.1051 /$ forest:2007048.

4. Candelier, K., Hannouz, S., Thevenon, M.F., Guibal, D., Gerardin, P., Petrissans, M., \& Collet, R. (2017). Resistance of thermally modified ash (Fraxinus excelsior L.) wood under steam pressure against rot fungi, soil-inhabiting micro-organisms and termites. Eur.J. Wood Prod., 75, 249-262. DOI: 10.1007/s00107-0161126-y.

5. Chaouch, M., Petrissans, M., Petrissans, A., \& Gerardion, P. (2010). Use of wood elemental composition to predict heat treatment intensity and decay resistance of different softwood and hardwood species. Polym. Degrad. Stabil. 95, 2255-2259. DOI: 10.1016/j.polymdegradstab.2010.09.010.

6. EN 1534, European Standard. (2000). Wood flooring - Determination of resistance to indentation - Test method.

7. EN 335-1, European Standard. (2006). Durability of wood and wood-based products - Definition of use classes - part 1: General.

8. Ferrari, S., Allegretti, O., Cuccui, I., Moretti, N., Marra, M., \& Todaro, L. (2013). A revaluation of Turkey oak wood (Quercus cerris L.) through combined steaming and thermo-vacuum treatments. Bioresources, 8(4), 5051-5066.

9. Gerardin, P. (2016). New alternatives for wood preservation based on thermal and chemical modification of wood - a review. Ann. For. Sci. 73, 559-570. DOI: 10.1007/s13595-015-0531-4.

10. Hill, C.A.S. (2006). Wood Modification: Chemical, Thermal, and Other Processes. West Sussex, England: John Willey \& Sons Ltd.

11. Hofmann, T., Wetzig, M., Retfalvi, T., Sieverts, T., Bergemann, H., \& Niemz, P. (2013). Heat-treatment with the vacuum-press dewatering method: chemical properties of the manufactured wood and the condensation water. Eur. J. Wood Prod. 71, 121-127. DOI: 10.1007/s00107-012-0657-0.

12. Homan, W.J., \& Jorissen, A.J.M. (2004). Wood modification developments. Heron, 49(4), 361-386.

13. Johansson, D., Sehlstedt-Persson, M., \& Moren, T. (2007). Effect of heat treatment on capillary water absorption of heat-treated pine, spruce and birch. In S. Kurjatko, J. Kudela \& R. Lagana (Eds), Wood Structure and Properties (pp. 251-255). Zvolen, Slovakia: Arbora Publishers.

14. Kamdem, D.P., Pizzi, A., \& Jermannaud, A. (2002). Durability of heat-treated wood. Holz als Roh-und Werkstoff, 60(1), 1-6. DOI: 10.1007/s00107-001-0261-1.

15. Metsä-Kortelainen, S., \& Viitanen, H. (2010). Effect of fungal exposure on the strength of thermally modified Norway spruce and Scots pine. Wood Material Science and Engineering, 1, 13-23.

16. Militz, H., \& Altgen, M. (2014). Processes and properties of thermally modified wood manufactured in Europe. In T.P. Schultz, B. Goodell \& D.D. Nicholas (Eds.), Deterioration and protection of sustainable biomaterials (pp. 269-285). Washington, DC: American Chemical Society.

17. Rowell, R.M., Ibach, R.E., Mcsweeny, J., \& Nilsson, T. (2009). Understanding decay resistance, dimensional stability and strength changes in heat-treated and acetylated wood. Wood Materials Science and Engineering, 4, 14-22. DOI: 10.1080/17480270903261339.

18. Sandberg, D., Haller, P., \& Navi, P. (2013). Thermo-hydro and thermo-hydro-mechanical wood processing: An opportunity for future environmentally friendly wood products. Wood Material Science and Engineering, 8(1), 64-88. DOI: 10.1080/17480272.2012.751935.

19. Simpson, W., \& TenWolde, A. (1999). Physical properties and moisture relations of wood. In R.J. Ross (Ed.), Wood handbook: Wood as an engineering material (pp. 3.1-3.24). Madison, WI: Forest Products Laboratory.

20. Van Acker, J., Van den Bulcke, J., De Windt, I., Colpaert, S., \& Li, W. (2015). Moisture Dynamics of modified wood and the relevance towards decay resistance. In Proceedings of the Eight European Conference on Wood Modification, 26-27 October 2015 (pp. 44-55). Helsinki, Finland.

21. Wang, W., Zhu, Y., \& Cao, J. (2013). Evaluation of copper leaching in thermally modified southern yellow pine wood impregnated with ACQ-D. Bioresources, 8(3), 4687-4701. 
22. Welzbacher, C.R., Brischke, C., \& Rapp, A.O. (2007). Influence of treatment temperature and duration on selected biological, mechanical, physical and optical properties of thermally modified timber. Wood Material Science and Engineering, 2(2), 66-76. DOI: 10.1080/17480270701770606.

23. Welzbacher, C.R., Rassam, G., Talaei, A., \& Brischke, C. (2011). Microstructure, strength and structural integrity of heat-treated beech and spruce wood. Wood Material Science and Engineering, 6, $219-227$. DOI: 10.1080/17480272.2011.622411.

24. Widmann, R., Fernandez-Cabo, J.L., \& Steiger, R. (2012). Mechanical properties of thermally modified beech timber for structural purposes. Eur. J. Wood Wood Prod. 70(6), 775-784. DOI: 10.1007/s00107-0120615-x. 